\title{
Packing of Alumina Particles in 3D Preform of Mullite Fiber by Slurry Pressure-Infiltration
}

\author{
Soo-Man $\mathrm{Sim}^{\dagger}$ \\ School of Materials Science and Engineering, Hongik University, Sejong City 339-701, Korea \\ (Received October 4, 2013; Revised October 25, 2013; Accepted October 31, 2013)

\section{슬러리 가압함침에 의한 3D Mullite 섬유 Preform의 알루미나 입자 충전} \\ 심 수 만 ${ }^{\dagger}$ \\ 홍익대학교 재료공학부 \\ (2013년 10월 4일 접수 ; 2013년 10월 25일 수정 ; 2013년 10월 31일 채택)
}

\begin{abstract}
Well-dispersed slurries of submicron-sized alumina powders were pressure-infiltrated in 3D preforms of mullite fibers and the effects of the particle size and infiltration pressure on the particle packing characteristics were investigated. Infiltration without pressure showed that the packing density increased as the particle size decreased due to the reduction of the friction between the particles and the fibers. The infiltrated preforms contained large pores in the large voids between the fiber tows and small pores in the narrow voids between the individual fibers. Pressure infiltration resulted in a packing density of $77 \%$ regardless of the particle size or the infiltration pressure $(210 \sim 620 \mathrm{kPa})$. Pressure infiltration shortened the infiltration time and eliminated the large pores in preforms infiltrated with the slurries of smaller particles. The slurry pressure-infiltration process is thus an efficient method for the packing of matrix materials in various preforms.
\end{abstract}

Key words: Pressure infiltration, 3D Preform, Alumina slurry, Particle size, Packing density

\section{1. 서 론}

섬유보강 세라믹복합재료는 고온 구조재료로서 많은 관 심을 받고 있다. 특히, 3D 복합재료는 세라믹 섬유가 3차 원 형상으로 직조된 preform에 모재(matrix) 물질을 충전 하여 만든 새로운 고기능 복합재료로서, gas turbine의 shroud, 열교환기 부품, 로켓 노즐 등에 사용되고 있다.,2) 기존의 $2 \mathrm{D}$ 복합재료는 섬유 보강재의 배열 방향에 따라 강도가 달라지는 이방성을 지니지만, $3 \mathrm{D}$ 복합재료는 다 양한 직조방법을 사용하여 $2 \mathrm{D}$ 복합재료의 취약한 전단강 도를 개선할 수 있으므로 기계적 성질이 균일하면서도 복 잡한 형상을 제조할 수 있는 장점이 있다., ${ }^{3,4}$

$3 \mathrm{D}$ preform에 모재를 채우는 방법으로는 CVI(chemical vapor infiltration)와 졸 또는 고분자 전구체를 사용하는 용 액 함침이 이용되고 있다. ${ }^{5)} \mathrm{CVI}$ 는 주로 $\mathrm{SiC} / \mathrm{SiC}$ 복합재 료 제조에 이용되지만 모재 물질의 충전 효율이 낮아 함 침 시간이 매우 길고 preform의 복잡한 기공 구조로 인하

\footnotetext{
${ }^{\dagger}$ Corresponding author : Soo-Man Sim

E-mail : smsim@hongik.ac.kr

Tel : +82-44-860-2518 Fax : +82-44-862-2774
}

여 고밀도 충전이 어렵다. 그러므로 $3 \mathrm{D}$ 복합재료의 사용 은 고강도와 고인성이 요구되지 않는 부품에 한정되어 있 다. 졸을 사용하는 용액 함침은 졸의 고체 함량이 낮아 함침을 수차례 반복해야 하며, 건조와 소결 과정에서 preform은 수축하지 않고 모재 수축만이 일어나 균열이 생성되는 것이 문제이다. ${ }^{1,6)}$ 따라서 고강도, 고인성의 고 밀도 $3 \mathrm{D}$ 복합재료를 제조하려면 함침효율이 높아야 하는 데, preform에 모재 물질을 한 번에 최대한 충전시킬 수 있다면 CVI 시간을 단축하거나 용액 함침의 회수(inflitration cycle)를 현저히 줄일 수가 있다.

최근에는 슬러리 함침(slurry infiltration)을 이용하여 다 양한 형태의 preform에 모재 물질을 충전시키는 시도가 이루어지고 있다. ${ }^{7-10)}$ 이 방법은 입자가 잘 분산되어 있는 슬러리로 미세구조가 균일하고 밀도가 높은 성형체를 얻 을 수 있는 슬립 캐스팅과 유사하다. 그러나 preform의 기 공 구조가 매우 복잡하므로 충전밀도(packing density)는 슬러리의 분산 상태 외에도 입자 형상, 입자 크기와 분포 등에 영향을 받는다. ${ }^{2,11-13)}$ 본 연구에서는 mullite 섬유로 되어 있는 3D preform에 submicron 크기의 알루미나 분 말로 제조한 슬러리를 가압함침하고, 입자 크기와 함침 
압력이 preform의 입자 충전에 미치는 영향을 조사하였다.

\section{2. 실험방법}

슬러리 제조에는 입경이 각각 다른 세 종류(A15, A30, $\mathrm{A} 50)$ 의 알루미나 분말(AKP15, AKP30, AKP50, Sumitomo Chemical Co. Ltd, Japan)을 사용하였다. 알루미나 분말들 을 탈이온수와 혼합하고 초음파 분쇄(Ultrasonic Homogenizer 600W, Cole-Parmer Co., USA)로 약응집입자(soft agglomerate)들을 제거한 후, $0.1 \mathrm{M} \mathrm{HNO}_{3}$ 용액으로 $\mathrm{pH}$ 를 4로 조절하여 정전기적 안정화에 의해 입자가 잘 분산되 어 있는 슬러리를 만들었다. ${ }^{14)}$ 초음파로 분쇄되지 않은 강응집입자(hard agglomerate)들은 침강법으로 제거하였다. 슬러리를 filter press로 여과하여 얻은 분말을 다시 탈이 온수와 혼합하고 $\mathrm{pH}$ 를 조절하여 함침용 슬러리를 제조하 고, 슬러리의 고체 함량(solid loading)은 $20 \mathrm{vol} \%$ 로 하였다.

Preform은 직경이 $\sim 10 \mu \mathrm{m}$ 인 mullite 섬유(Nextel 440 , $3 \mathrm{M} \mathrm{Co.,} \mathrm{USA)를} \mathrm{multi-warp} \mathrm{weaving} \mathrm{법으로} \mathrm{직조한} \mathrm{3D}$ preform을 사용하였다. ${ }^{15)}$ Preform은 3D angle interlock woven fabric으로 부르며, 두께가 $0.25 \mathrm{~cm}$ 인 판상으로 40 $\mathrm{vol} \%$ 가 섬유로 채워져 있고 나머지 $60 \%$ 는 섬유 사이의 작은 기공과 섬유 다발(tow) 사이의 큰 공간으로 구성되 어 있다. Preform은 $600^{\circ} \mathrm{C}$ 의 공기 중에서 1 시간 가열하여 sizing을 제거하였다.

슬러리 함침에는 filter press(YT30 142HW, Millipore Co., USA)에 다공질의 금속 filter 지지대를 부착하여 nylon filter가 함침 압력에 견딜 수 있도록 하였다. 함침은 preform 시편을 filter 위에 놓고 슬러리를 주입한 다음, filter press 하단부에 진공을 가하여 슬러리의 액체가 잘 배출되도록 하였다. 액체가 더 이상 배출되지 않을 때까 지 6 시간 이상 진공을 유지하여 입자들이 preform에 충 분히 충전되도록 하였다. 가압 함침은 filter press 상단부 에 압축공기를 주입하여 $210 \mathrm{kPa}$ 에서 $620 \mathrm{kPa}$ 까지 가압 하고 액체가 더 이상 배출되지 않을 때까지 압력을 일정 하게 유지하였으며, 함침시간은 2 3시간 소요되었다. 함 침한 시편은 기공률 측정과 미세구조 관찰에 필요한 최 소한의 강도를 얻기 위하여 $800^{\circ} \mathrm{C}$ 에서 1 시간 동안 소결 한 후, 시편 표면을 preform 상단부와 하단부가 노출될 때 까지 연마하고 $1.0 \times 1.0 \mathrm{~cm}^{2}$ 크기로 절단하였다.

분말의 입도분포는 레이저회절 입도분석기(SALD-2001, Schimadzu, Japan)로 측정하였으며, preform의 충전밀도는 Archimedes 법으로 측정한 개기공률(open porosity \%)로부 터 구하였다. 시편의 체적 부피(bulk volume)를 $100 \mathrm{vol} \%$ 로 하고 개기공률을 제외한 $\mathrm{vol} \%$ 를 충전밀도로 하였다. 따라서 충전밀도에는 입자 외에 preform 섬유가 차지하는 부피와 Archimedes 법으로 측정할 수 없는 폐기공(closed pore)의 부피가 포함되어 있다. 함침 시편의 미세구조는
시편을 epoxy로 진공 함침하고 $0.1 \mu \mathrm{m}$ 크기의 diamond paste로 연마한 후 SEM(S-2400, Hithchi, Japan)과 광학현 미경(OPTIPHOT-100S, Nikon, Japan)으로 관찰하였다.

\section{3. 결과 및 고찰}

본 연구에서 사용된 $3 \mathrm{D}$ preform은 기공 구조가 매우 복 잡하여 입자 충전은 슬러리의 분산 상태 외에도 입자 형 상, 입자 크기 및 분포 등에 영향을 받는다. 슬립 캐스팅 의 경우에서와 같이 분산이 잘 된 슬러리는 응집이 된 슬 러리 보다 충전효율(packing efficiency)이 높고 미세구조 도 균일하다. 입자들은 슬러리가 preform의 기공 통로(pore channel)를 막지 않고 잘 침투할 수 있을 정도로 충분히 작아야 한다. 미세한 입자일수록 섬유 사이의 공간을 치 밀하게 충전시킬 수 있다.,12) 또한, 불규칙한 형상과 거 친 표면을 지닌 응집입자는 슬러리가 기공 통로를 지날 때 발생하는 입자와 섬유 사이의 마찰로 인하여 슬러리 의 유동을 방해하므로 충전효율이 낮아진다. 특히, preform 의 기공 통로가 매우 좁거나 입자가 크면 마찰의 영향은 더욱 커진다. ${ }^{2,12}$

Fig. 1은 A50 알루미나 분말(as-received)과 이 분말을 초 음파 분쇄하고 침강법으로 큰 응집입자를 제거한 분말 (fractionated)의 입도 분포이다. 큰 응집입자를 제거한 결 과, 평균 입경은 $0.3 \mu \mathrm{m}$ 에서 $0.2 \mu \mathrm{m}$ 으로 약간 작아졌으나 분말에 $~ 8 \%$ 존재하던 큰 입자들 $(>0.7 \mu \mathrm{m})$ 은 완전히 제 거되었고 작은 입자들 $(<0.1 \mu \mathrm{m})$ 이 $\sim 6 \%$ 에서 $\sim 15 \%$ 로 증가 하였다. 두 분말로 만든 슬러리로 함침한 결과, 큰 응집 입자들은 입자 충전을 방해하여 충전밀도가 $75 \%$ 에 불과 한 반면에 큰 응집입자를 제거한 후에는 충전밀도가 $80 \%$ 로 증가하였다.

Fig. 2는 알루미나 분말(A15, A30, A50)을 초음파 분쇄 와 침강을 이용하여 응집입자를 제거한 후의 입도분포이

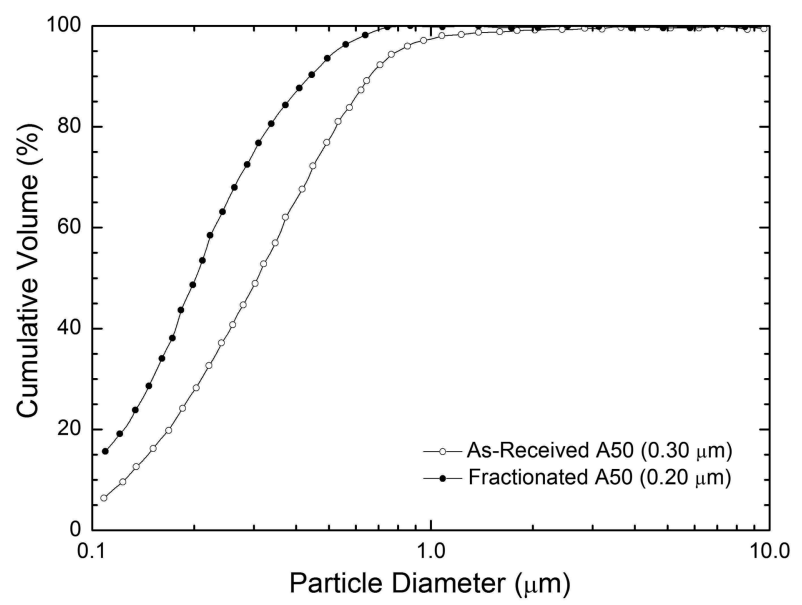

Fig. 1. Particle size distributions of as-received and fractionated (sonicated and sedimented) A50 alumina powders. 


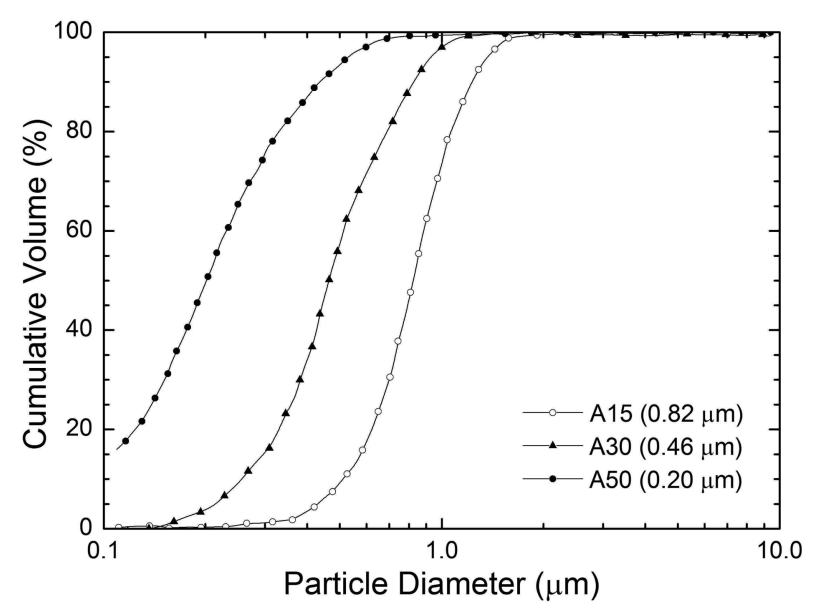

Fig. 2. Particle size distributions of various alumina powders (A15, A30, and A50).

다. $\mathrm{A} 15, \mathrm{~A} 30$ 분말은 평균 크기가 $0.82,0.46 \mu \mathrm{m}$ 이며, $1 \mu \mathrm{m}$ 보다 큰 입자들이 $\mathrm{A} 15$ 분말에는 $~ 25 \%, \mathrm{~A} 30$ 분말 에는 $~ 5 \%$ 가 존재하고 있다. Table 1 은 이 슬러리들로 제 조한 분말 성형체와 함침한 preform의 충전밀도를 나타낸 것이다. Preform의 충전밀도는 섬유가 차지하는 부피가 포함되어 분말 성형체와 직접 비교하기 어려우므로 $60 \%$ 의 preform 공간에 충전된 입자만의 부피를 고려한 충전 효율을 함께 나타내었다.

Preform의 충전에 요구되는 입자의 특성은 분말 성형체 를 제조하는 경우와 다른 것으로 나타났다. 분말 성형체 의 충전밀도는 입자 크기에 영향을 받지 않지만, 가압하 지 않고 함침한 preform의 충전밀도는 입자 크기에 큰 영 향을 받았다. 세 슬러리를 슬립 캐스팅으로 만든 분말 성 형체는 모두 $67 \sim 68 \%$ 의 충전밀도를 나타내었다(Table 1). 그러나 함침한 preform의 경우는 입자 크기가 작아지면 충 전밀도가 $73 \%$ 에서 $80 \%$ 까지 증가하였다. 큰 입자들 $(>1 \mu \mathrm{m})$ 이 $25 \%$ 가 되는 $\mathrm{A} 15$ 슬러리는 충전밀도가 가장 낮았고, 큰 입자들 $(>1 \mu \mathrm{m})$ 이 없고 미세한 입자 $(<1 \mu \mathrm{m})$ 들이 $15 \%$ 존재하는 $\mathrm{A} 50$ 슬러리가 충전밀도가 가장 높게 나타났다. 이 결과로 보아 preform의 좁고 긴 기공 통로에서는 입자 가 클수록 입자와 섬유 사이의 마찰이 커져서 슬러리가 통과하는 것을 방해하여 충전밀도가 낮아진다고 볼 수 있다. ${ }^{2)}$

분말 성형체의 경우는 입자와 캐스팅 용기 벽과의 마
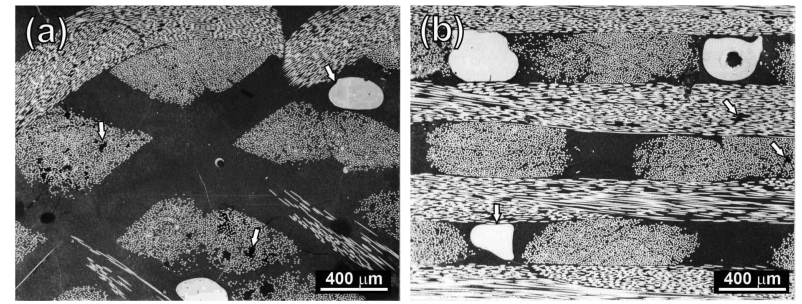

Fig. 3. Optical micrographs of 3D preform infiltrated with A30 slurry without pressure: (a) top and (b) side (Arrows indicate pores).

찰 효과를 무시할 수 있다. Table 1 에서와 같이 충전효율 즉 preform 공간에 입자가 차지하는 부피가 $67 \%$ 인 A50 슬러리가가 분말 성형체의 충전밀도와 거의 동일하므로 세 슬러리 중에서 입자와 섬유 사이의 마찰이 가장 적은 것으로 판단된다.

Fig. 3은 A30 슬러리를 가압하지 않고 함침한 preform 단면의 광학현미경 사진이다. 슬러리의 함침 통로(infiltration channel)로 보이는 매우 큰 기공(epoxy로 채워져 밝게 보 이는 부분)이 섬유 다발 사이의 큰 공간에서 발견되었고, 매우 작은 기공(어두운 부분)들도 섬유 사이의 좁은 공간 에서 발견되었다. 이 기공들은 복잡한 preform 구조 때문 에 상단부(Fig. 3(a)) 보다 슬러리의 유동이 더 어려운 측 면부(Fig. 3(b))에서 많이 관찰되었다. 또한 입자들이 치밀 하게 충전된 부분에서는 건조과정에서 발생한 것으로 추 정되는 균열이 나타났다.

가압하지 않은 함침과는 대조적으로 $345 \mathrm{kPa}$ 의 압력으 로 함침한 슬러리의 충전밀도는 입자 크기에 관계없이 $76 \sim 77 \%$ 로 나타났다(Table 1). 함침압력은 함침시간을 2 3 시간으로 크게 단축하였으나, 모든 슬러리의 충전효율을 향상시키지 못하였다. A15, A30 슬러리의 경우에는 함침 압력이 마찰 효과를 감소시켜 충전효율은 가압하지 않은 함침의 $55 \%, 60 \%$ 에 비하여 각각 $5 \%, 2 \%$ 증가하였다. 반 면에 $\mathrm{A} 15, \mathrm{~A} 30$ 슬러리 보다 입자가 작은 $\mathrm{A} 50$ 슬러리는 충전효율이 $5 \%$ 감소하였다.

Fig. 4와 Fig. 5 는 $345 \mathrm{kPa}$ 의 압력에서 함침한 preform 의 단면 사진으로, Fig. 4는 A15, A30 슬러리로, Fig. 5는 $\mathrm{A} 50$ 슬러리로 함침한 것이다. A15 슬러리로 함침한 preform에서는 Fig. 3 에서와 같은 매우 큰 기공과 작은 기 공이 미세한 균열과 함께 관찰되었다(Fig. 4(a)와 (b)). 그

Table 1. Particle Size Characteristics and Packing Densities of Alumina Powder Compacts and Infiltrated Preforms

\begin{tabular}{|c|c|c|c|c|c|}
\hline \multirow{2}{*}{ Sample ID } & \multirow{2}{*}{ Mean Particle Size $(\mu \mathrm{m})$} & \multirow{2}{*}{ Standard Deviation $(\mu \mathrm{m})$} & \multicolumn{3}{|c|}{ Packing Density (\%) } \\
\hline & & & Bulk $^{\mathrm{a}}$ & Preform $^{b}$ & Preform \\
\hline A15 & 0.82 & 1.48 & 67 & $73(55)^{d}$ & $76(60)$ \\
\hline $\mathrm{A} 30$ & 0.46 & 1.60 & 67 & $76(60)$ & $77(62)$ \\
\hline $\mathrm{A} 50$ & 0.20 & 1.72 & 68 & $80(67)$ & 77 (62) \\
\hline
\end{tabular}

${ }^{\mathrm{a}}$ Bulk compact cast without pressure, ${ }^{\mathrm{b}}$ preform infiltrated without pressure, ${ }^{\circ}$ preform infiltrated at $345 \mathrm{kPa}$, and ${ }^{\mathrm{a}}$ packing efficiency. 

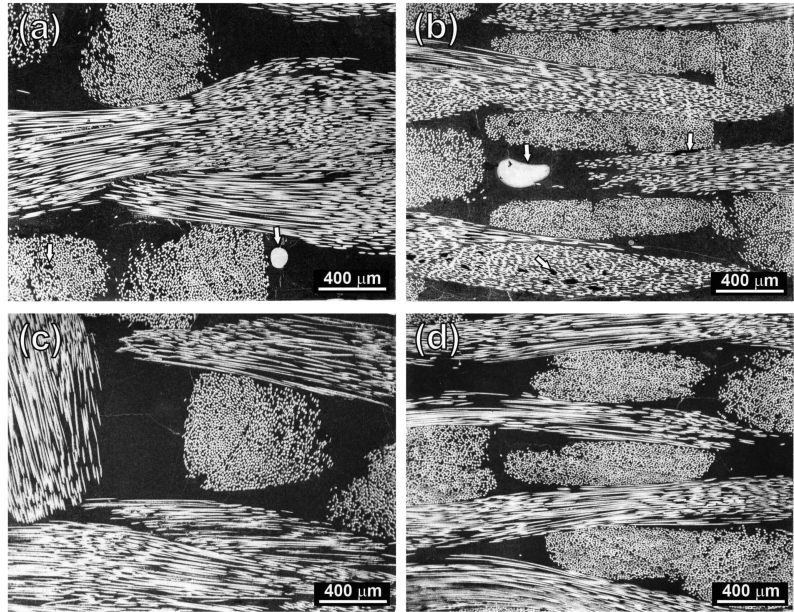

Fig. 4. Optical micrographs of preforms infiltrated with A15 and A30 slurries at $345 \mathrm{kPa}$ ((a) and (c): top and (b) and (d): side). (Arrows indicate pores.)
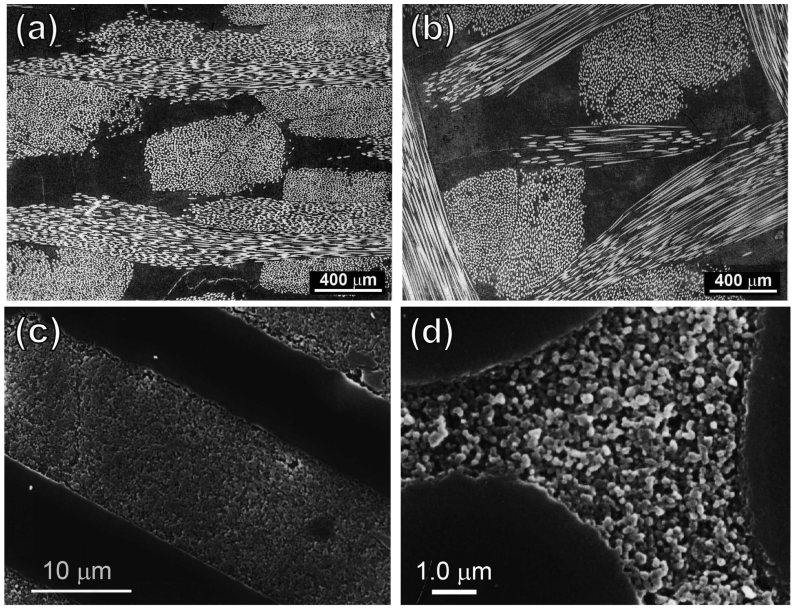

Fig. 5. Micrographs of preforms infiltrated with A50 slurry at $345 \mathrm{kPa}$ (optical micrographs: (a) top and (b) side and SEM images: (c) and (d)).

러나 A30 슬러리(Fig. 4(c)와 (d))와 A50 슬러리(Fig. 5(a) 와 (b))로 함침한 preform에는 큰 기공들이 발견되지 않았 다. Fig. 5의 (c)와 (d)는 고배율 사진으로 미세한 균열과 함께 알루미나 입자들이 수 $\mu \mathrm{m}$ 크기의 섬유 사이의 공 간에 치밀하게 충전되었음을 보여 주고 있다. 따라서 가 압함침은 $\mathrm{A} 30, \mathrm{~A} 50$ 슬러리의 경우, 큰 기공을 제거하여 미세구조를 균일하게 하는 효과는 있으나, 충전밀도가 비 슷하므로 작은 기공과 균열 등의 많은 결함들이 여전히 존재하는 것으로 보인다.

Fig. 6은 A30 슬러리를 $210 \mathrm{kPa}$ 부터 $620 \mathrm{kPa}$ 까지 가압 함침한 preform의 충전밀도로 함침 압력에는 무관하게 충 전밀도는 $76 \sim 77 \%$ 로 나타났다. 이 충전밀도는 $2 \mathrm{D}$ preform 에 슬러리를 함침한 결과보다 우수하였다. Coyle 등ํㅡ는 $\mathrm{SiC}$ 섬유를 일축 방향으로 배열한 preform에 알루미나 슬

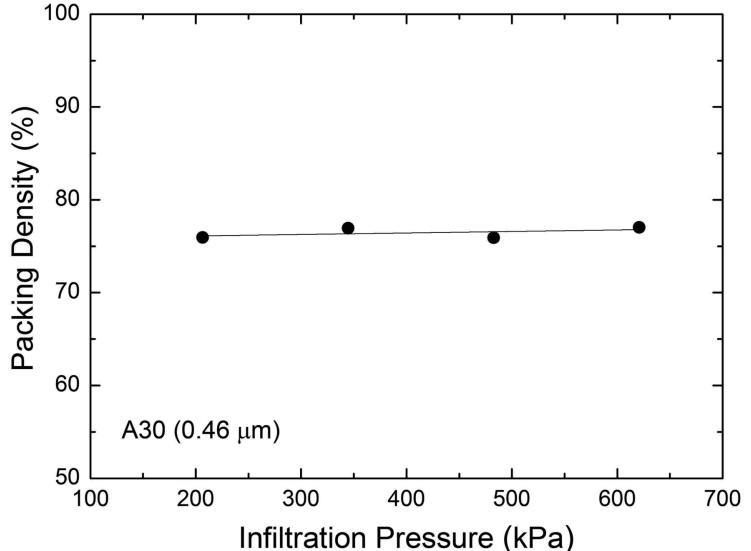

Fig. 6. Packing densities of A30 slurry in preform as a function of infiltration pressure.

러리를 $0.6 \sim 1 \mathrm{MPa}$ 의 압력으로 함침하여 $64 \%$ 의 충전밀 도를 얻었다고 하였다.

가압함침은 가압 캐스팅(pressure casting)으로 성형체를 제조할 때 보다 압력이 낮지만 압력에 따라 충전밀도가 변하지 않는 것은 가압 캐스팅과 동일하였다. ${ }^{12,16,17)}$ Lange 과 Miller ${ }^{12)}$ 는 잘 분산된 $20 \mathrm{vol} \%$ 의 알루미나 슬러리를 사용하여 성형밀도는 $\sim 0.5 \mathrm{MPa}$ 이상에서 압력에 무관하 며, $80 \mathrm{MPa}$ 에서 $70 \%$ 를 얻었다고 하였다. 응집되어 있는 슬러리의 경우에는 $1 \mathrm{MPa}$ 에서 $54 \%$ 인 성형밀도가 압력에 따라서 점차 증가하였으나 $100 \mathrm{MPa}$ 에서는 $62.5 \%$ 에 불과 하였다. ${ }^{18)}$ 또한 캐스팅 압력이 너무 높으면 압축된 성형 체가 압력이 제거될 때 발생하는 탄성복귀효과(spring-back effect) 때문에 성형체에 균열이 발생한다고 하였다. ${ }^{17,18)}$ 알루미나 슬러리에서는 $50 \sim 100 \mathrm{MPa}$ 의 압력에서 $2 \sim 3 \%$ 의 strain recovery가 일어나는 것으로 알려져 있으나 본 연구에서는 함침압력이 이보다 훨씬 낮으므로 이러한 균 열은 발생하지 않는 것으로 간주된다. ${ }^{12)}$

\section{4. 결 론}

입자 크기가 다른 알루미나 분말 슬러리를 3D preform에 가 압함침하여 입자 크기와 함침압력이 입자 충전에 미치는 영향을 조사하였다. 가압하지 않고 함침한 preform의 충 전밀도는 평균 입경이 $0.82 \mu \mathrm{m}$ 에서 $0.2 \mu \mathrm{m}$ 으로 작아질 수록 입자와 섬유 사이의 마찰이 감소하여 $73 \%$ 에서 $80 \%$ 로 증가하였다. 함침한 preform에는 섬유 다발 사이의 큰 공간에 슬러리의 함침 통로로 보이는 매우 큰 기공과 섬 유 사이의 좁은 공간에서 작은 기공들이 존재하였다. 함 침압력 $345 \mathrm{kPa}$ 에서는 입자 크기에 관계없이 $77 \%$ 의 충 전밀도를 얻을 수 있었다. 가압함침은 함침시간을 단축시 키며 입자 크기가 작을 때는 큰 기공을 제거하여 미세구 조를 균일하게 하는 효과는 있으나, 충전 효율에는 영향 
을 주지 않았다. 함침압력을 $210 \mathrm{kPa}$ 에서 $620 \mathrm{kPa}$ 까지 증 가하여도 충전밀도는 압력에 무관하였다.

\section{REFERENCES}

1. T. W. Coyle, M. H. Guyot, and J. F. Jamet, "Mechanical Behavior of a Microcracked Ceramic Composite," Ceram. Eng. Sci. Proc., 73 [1] 947-57 (1990).

2. F. F. Lange, D. C. Lam, O. Sudre, B. D. Flinn, C. Folsom, B. V. Velamakanni, F. W. Zok, and A. G. Evans, "Powder Processing of Ceramic Matrix Composites," Mater. Sci. Eng. A, 144 [1-2] 143-52 (1991).

3. F. Ko, M. Koczak, and G. Layden, "Structural Toughening of Glass Matrix Composites by 3-D Fiber Architecture," Ceram. Eng. Sci. Proc., 8 [7-8] 822-31 (1987).

4. Y-M. Yang, J-C. Chou, and C. V. Burkland, "Fracture Behavior of 3-D Braided Nicalon/Silicon Carbide Composite," pp. 163-169 in Mat. Res. Symp. Proc., Vol. 120, High-Temperature/High-Performance Composites. Ed. by F. D. Lemkey, A. G. Avans, S. G. Fishman, and J. R. Strife, Materials Research Society, Pittsburgh, PA., 1988.

5. J. R. Strife, J. J. Brennan, and K. M. Prewo, "Status of Continuous Fiber-Reinforced Ceramic Matrix Composite Processing Technology," Ceram. Eng. Sci. Proc., 11 [7-8] 871919 (1990).

6. A. Dey, N. Kayal, and O. Chakrabarti, "Preparation of Porous SiC Ceramics by an Infiltration Technique," Ceram. Int., 37 223-30 (2011).

7. Y. Zhu, Z. Huang, S. Dong, M. Yuan, and D. Jiang, "Manufacturing 2D Carbon-Fiber-Reinforced SiC Matrix Composites by Slurry Infiltration and PIP Process," Ceram. Int., 34 1201-05 (2008).

8. J. J. Brennan, "Interfacial Characterization of A Slurry-Cast Melt-Infiltrated SiC/SiC Ceramic-Matrix Composites," Acta
Mater., 48 4619-28 (2000).

9. U. F. Vogt, M. Gorbar, P. Dimopoulos-Eggenschwiler, A. Broenstrup, G. Wagner, and P. Colombod, "Improving the Properties of Ceramic Foams by a Vacuum Infiltration Process," J. Eur. Ceram. Soc., 30 [15] 3005-11 (2010).

10. J. Magnant, R. Pailler, Y. Le Petitcorps, L. Maille, A. Guette, J. Marthe, and E. Phillippe, "Fiber-Rinforced Ceramic Matrix Composites Processed by a Hybrid Technique Based on Chemical Vapor Infiltration, Slurry Impregnation and Spark Plasma Sintering," J. Eur. Ceram. Soc., 33 [1] 181-90 (2013).

11. T. L. Starr, "Packing Density of Fiber/Powder Blends," Am. Ceram. Soc. Bull., 65 [9] 1293-96 (1986).

12. F. F. Lange and K. T. Miller, "Pressure Infiltration: Consolidation and Kinetics and Mechanics," Am. Ceram. Soc. Bull., 66 [10] 1498-504 (1987).

13. J. V. Milewski, "Advanced Packing Theory Predicts Super Ceramic Composites," Ceram. Eng. Sci. Proc., 12 [7-8] 1095-112 (1991).

14. T.-S. Yeh and M. D. Sacks, "Effect of Green Microstructure on Sintering of Alumina," pp. 309-331 in Ceramic Transactions, Vol. 7, Sintering of Advanced Ceramics. Ed. by C. A. Handwerker, J. E. Blendell, and W. Kaysser, The American Ceramic Society, Inc., Westerville, OH., 1990.

15. F. K. Ko, "Preform Fiber Architecture for Ceramic-Matrix Composites," Am. Ceram. Soc. Bull., 68 [2] 401-14 (1989).

16. T. J. Fennelly and J. S. Reed, "Compression Permeabiliy of $\mathrm{Al}_{2} \mathrm{O}_{3}$ Cakes Formed by Pressure Slip Casting," J. Am. Ceram. Soc., 55 [8] 381-83 (1972).

17. M. N. Rahaman, Ceramic Processing; pp. 305-08, CRC Press, Boca Ranton, 2007.

18. F. F. Lange, "Powder Processing Science and Technology for Increased Reliability," J. Am. Ceram. Soc., 72 [1] 3-15 (1989). 